\title{
политология
}

POLITICS

\author{
DOI: 10.12731/2070-7568-2017-2-45-60 \\ УДК 11.25.40
}

\section{ОСОБЕННОСТИ \\ СОЦИАЛЬНО-ПОЛИТИЧЕСКОГО ПРОЦЕССА В США}

\section{Бейдина T.Е., Бейдина А.P.}

Предметом исследования в данной статье является как политическое, так и социальное развитие США в современный период. Американская традиция в исследовании политических процессов имеет четыре этапа. Первый этап связан с обоснованием места исполнительной, законодательной и судебной властей в политической системе (работы Ф. Поллака и Р. Сили). Второй этап - это бихевиористское изучение политики (работы Г. Лассуэлла и Ч. Мерриама). Ч. Мерриам помимо того, что сравнивал проиессы, изучал их сходства и различия. Третий этап-характеризуется изучением политических систем (Т. Парсонс, Д. Истон, Р. Арон, Г. Алмонд и К. Дойч). Четвертый этап связан со сверхдержавностью и проблемой демократизации систем (С. Хантингтон, Зб. Бжезинский). Социальные процессы в США оценивались Р. Парком, П. Сорокиныл, Э. Гидденсом. Работа ориентирована как на раздельное обоснование сочиальных и политических прочессов США, так и на отражение единства американской соииальнополитической реальности.

Научная новизна состоит в обосновании концепта «соџиально-политический прочесс в США» с характеристикой его особенностей. Для социально-политического проиесса США характерно 
действие по двум каналам: мягкая сила и агрессия. Мягкая сила проявляется в доминировании экономики США. Основными выводами проведенного исследования можно отметить особенности соичильно-политического прочесса в США.

Цель - уточнить понятие «сочиильно-политический процесс в США» и дать оченку направлениям его исследования в рамках американской политической традиции.

Метод или методология проведения работы: в статье использовались методы: системный, сравнительно-исторический и структурно-функииональный.

Результаты: в результате работы проанализированы направления исследования социально-политических процессов и осуществлен анализ динамики сочиильно-политических процессов в США.

Область применения результатов: полученные результаты иелесообразно применять в теории и практике международных отномений.

Ключевые слова: социально-политический процесс; США; мягкая сила; агрессия.

\section{FEATURES OF THE SOCIO-POLITICAL PROCESS IN THE UNITED STATES}

\section{Beydina T.E., Beydina A.R.}

The subject of this article is the study of political and social developments of the USA at the present stage. There are four stages of the American tradition of studying political processes. The first stage is connected with substantiation of the Executive, Legislative and Judicial branches of political system (works of F. Pollack and R. Sili). The second one includes behavioral studies of politics. Besides studying political processes Charles Merriam has studied their similarities and differences. The third stage is characterized by political system studies - the works of T. Parsons, D. Easton, R. Aron, G. Almond and K. Deutsch. The fourth stage is characterized by superpower and the systems de- 
mocratization problem (S. Huntington, Zb. Bzhezinsky). American social processes were qualified by R. Park, P. Sorokin, E. Giddens. The work is concentrated on the divided explanation of social and political processes of the us and the reflection of unity of American social-political reality.

Academic novelty is composed of substantiation of the US social-political process concept and characterization of its features. The US social-political process is characterized by two channels: soft power and aggression. Soft power appears in the US economy dominancy. The main results of the research are features of the socio-political process in the United States.

Purpose: the main goal of the research is to systematize the definition of social-political process of the USA and estimate the line of its study within American political tradition.

Methodology: in this article have used methods: such as system, comparison and historical analysis, structural-functional analysis.

Results: during the research the analysis of the dynamics of social and political processes of the United States had been made.

Practical implications it is expedient to apply the received results in the international relation theory and practice.

Keywords: political and social process; USA; soft power; aggression.

В политологии становятся все более актуальными вопросы об особенностях социально-политического процесса США, смене мирового лидера и о типах международного поведения. Характерно высказал свою позицию классик международных отношений Г. Моргентау: «Международная политика, как и любая политика, - это борьба за влияние... Любая политика, будь то внутренняя или внешняя, выявляет три базовые модели, либо к сохранению мощи, либо к усилению мощи, либо к демонстрации мощи» [5, с. 502-503]. Эти слова служат подтверждением существования трех типов современного международного поведения: стремится к сохранению мощи - Российская Федерация, усиливает мощь - КНР, демонстрирует мощь - США. 
Актуализируют значимость динамики социально-политических процессов США для современной политической науки следующие обстоятельства: 1. Исследований на основании истории политических учений в рамках политического процесса США не проводилось. 2. Авторское видение ориентировано на учет социального значения политического процесса и подчеркивание взаимосвязи социального и политического. Предлагаемый концепт «социально-политический процесс» применительно к США вполне обоснован. 3. Расширение проблематики социально-политического процесса в США.

В современный период становятся важными вопросы как политического, так экономического и военного развития США. Президент США Д. Трамп намерен провести глубокую реформу системы приобретения вооружений, широко внедрить подходы, применяемые в коммерческом секторе, превратить министерство обороны в «бизнес ведомство». По словам министра обороны США Д. Мэттиса, особое внимание будет обращено на поиск и скорейшее внедрение инноваций. Новый президент намерен уделять большое внимание развитию военно-промышленной базы. В структуре администрации создан Национальный совет по торговле, одной из задач которого является анализ состояния указанной базы и оценка возможности увеличения числа рабочих мест. «Совет будет консультировать президента по применению инновационных стратегий при ведении торговых переговоров, координировать с другими учреждениями оценки производственного потенциала США и военно-промышленной базы, помогать безработным американским рабочим встроиться в квалифицированный производственный сектор. Так, например, результатом наращивания программы строительства боевых кораблей может стать увеличение числа рабочих мест на 15-20 тысяч» [10].

Национальный совет по торговле будет работать в тесном взаимодействии с Советом национальной безопасности, Национальным советом по экономике и Национальным советом по внутренней политике. «Впервые в Белом доме будет создан совет, в центре внимания которого будут проблемы американских производителей 
и рабочих, который будет стратегически думать о здоровье американской военно-промышленной базы, роли торговли и производства в национальной безопасности» [10], - говорят в администрации Д. Трампа. Национальный совет по торговле будет руководить также программой Д. Трампа «Покупай американское, нанимай американца», имеющей целью увеличение числа рабочих мест в США. Возглавил совет профессор экономики Питер Наварро, являющийся одновременно советником президента по торговле и промышленной политике. Попытки Д. Трампа объединить внутренние и внешние экономические, политические, военные и идеологические изменения актуализируют проблему динамики социально-политических процессов США.

Существуют следующие направления исследования динамики социально-политических процессов в США:

1. Сущность и специфику американской политической традиции исследовали в рамках власти и коммуникаций: Г. Алмонд, С. Верба, С. Хантингтон, Н. Най $[12,1987]$.

2. Важно изучение Т. Парсонсом политической системы: «Политическая система включает три функциональных подсистем экономическую подсистему, подсистему интеграций и подсистему поддержания культурных образцов» [6, с. 479]. С позиции развития изменений значимо следующее утверждение Т. Парсонса «Равновесие характеризует, конечно, всю систему, а не отдельные ее части» [6, с. 483-484]. Совершенно очевидно, что развитие касается всей системы, так же как и ей присущи изменения.

3. Американская традиция в исследовании политических процессов имеет четыре этапа. Первый этап связан с обоснованием места исполнительной, законодательной и судебной властей в политической системе (работы Ф. Поллака и Р. Сили). Второй этап это бихевиористское изучение политики (работы Г. Лассуэлла и Ч. Мерриама). Ч. Мерриам имел следующие достижения в политических исследованиях [4, с. 176]:

- отмечал экономическую, социальную интерпретацию всех политических явлений; 
- исследовал географическую среду с точки зрения ее влияния на политические процессы;

- изучал факты этнического и биологического характера, выявляя отношения между политическими феноменами и их окружениями;

- проводил математический анализ политических процессов, в том числе с позиции окружающей среды и исторического роста.

Третий этап - характеризуется изучением политических систем (Т. Парсонс, Д. Истон, Р. Арон, Г. Алмонд и К. Дойч). Д. Истон исследовал «функционирование политических систем и оценивал политические изменения как сложный комплекс процессов» [3, с. 630], давал характеристику адаптаций как приспособление к изменяющимся условиям [3, с. 631]. Р. Арон в работе «Демократия и тоталитаризм» осуществил сравнительный анализ политических систем [2, с. 508]. Г. Алмонд проводил сравнительный анализ «культурно-личностных или психокультурных исследований политических феноменов» [1].

Четвертый этап связан со сверхдержавностью и проблемой демократизации систем (С. Хантингтон, Зб. Бжезинский).

Социальные процессы в США оценивались Р. Парком, П. Сорокиным, Э. Гидденсом. Для характеристики динамики социальнополитических процессов в США важно подчеркнуть взаимосвязь, как политического, так и экономического развития США, что также проявляется в истории политических учений в рамках политического процесса. Так, создатель структурно-функционального метода, используемого в политической науке, Т. Парсонс отмечает: «Существует круговое движение между политической сферой и экономикой, суть его в обмене фактора политической эффективности - в данном случает в участии в контроле над продуктивностью экономики - на экономический результат состоящий в контроле над ресурсами» [6, с. 483-484]. Аналогичной позиции придерживается разработчик сравнительного анализа политических систем Р. Арон: «Способ правления не может рассматриваться отдельно от экономического и социального устройства» [2, с. 522-523]. 
Отметив взаимосвязь экономических, социальных и политических характеристик, выделяем, что преобладающим концептом политологии является понятие «политический процесс». Политический процесс, в работе А. Бентли «Процесс управления» (1908), характеризуется постоянным образованием и распадом различных общественных объединений - групп интересов [13]. Политический процесс включает: «субъекты и участники процесса; объект процесса; средства, методы, ресурсы, которые связывают субъект и объект-цель» [8]. Субъектами политического процесса внутригосударственного и международного уровня являются регионы. Один из классиков политологии Ч. Мерриам писал: «Реальные политические процессы постепенно воспроизводятся в различных точках мира и на разных стадиях» [4, с. 179].

Наш авторский подход связан с тем, что категория «политический процесс» описывает, в первую очередь, динамические процессы адаптации и сохранения политических систем, что имеет социальное значение. Поэтому правомерно использовать концепт «социально-политический процесс», который, по нашему мнению, отличается от политического по многим параметрам.

Для социально-политического процесса США характерно действие по двум каналам: мягкая сила и агрессия. Мягкая сила проявляется в доминировании экономики США и расширении на Европу, АТР «массовой культуры». Доминирующий метод преобладания США - это агрессия, особенно ярко проявляющаяся во внешнеполитическом курсе Америки (Югославия, Афганистан, Ирак, Ливия, Сирия). «Массированное возмездие» обуславливает усиление политических рисков США.

Существуют и социальные риски населения США:

1. Высокая плата за медицинскую помощь. Для богатых американцев это не проблема, ведь существует ещё и медицинское страхование. Но для более бедных семей, особенно для тех, кто не работает, позволить себе подлечиться очень сложно. Что касается русских иммигрантов, то им легче зарабатывать деньги в США, но приезжать лечиться на родину. Ведь заработные платы не позволять получать медицинскую помощь в Америке. 
2. Высокая плата за обучение. Конечно, после завершения обучения, эти деньги окупаться с лихвой, но для среднестатистической семьи в Америке, очень сложно платить за обучение своих детей.

3. Продолжительность жизни более обеспеченного населения выше, чем бедных американцев. Существует слишком большой социальный разрыв.

4. Загрязнённый воздух и вся экология в больших городах, таких как Нью-Йорк, Сан-Франциско, Лас-Вегас. Слишком часто появляется смог в городах и даже в пригородах.

5. Большие пробки на дорогах. Много людей, что приводит к стрессам и хронической усталости жителей больших городов. Не говоря уже и о преступлениях, процент которых с каждым годом повышается.

6. Стрельба в школах. В каждом учебном заведении при входе стоят датчики обнаружения оружия и надёжная охрана.

7. В малообеспеченных пригородах или районах города, массово продают наркотики не только преступники, но и подростки, которые так зарабатывают себе на жизнь.

Таковы некоторые социальные характеристики процесса в США, которые, безусловно, влияют на политический процесс, обуславливая его риски и многовариантность.

Политический процесс США связан с электоральными характеристиками. Сначала несколько слов о выборах в законодательный орган США - Конгресс, который состоит из Сената и Палаты представителей. Члены Палаты представителей избираются на два года, а сенаторы на 6 лет. Отличительной особенностью американской политики является то, что действующие члены Конгресса переизбираются на следующий срок в очень большом масштабе.

Это происходит по следующим причинам.

1. Границы избирательных округов формируются таким образом, чтобы обезопасить действующих конгрессменов от проигрыша. Так как законодатели прекрасно знают, где живет большинство их избирателей, они часто делают гарантированные округи для демократов или республиканцев. Такая практика называется 
Gerrymandering и берет начало с 1812 г., тогда губернатор Элбридж Герри подписал распоряжение о перекройке границ одного из избирательных округов в пользу своей партии. Когда новые границы округа изобразили на карте, он стал напоминать по виду саламандру (salamander). Оттуда и пошло слово gerrymander, обозначающее перекройку границ избирательных округов в пользу правящих в них политических партий.

2. Действующие члены Конгресса обязательно принимают решения, выгодные для избирателей их округов. Такая практика называется «pork» и ее суть состоит в том, чтобы привлечь деньги в свои округа и решить какие-то важные проблемы избирателей в обмен на свое переизбрание. Понятно, что новые кандидаты не имеют таких финансовых возможностей.

3. Доступ к телевидению и другим медиа в более широком масштабе.

4. Участие в выборах очень дорогое дело. Претенденты просто бояться того, что они не смогут собрать достаточно денег для эффективной кампании в медиа.

5. Политические партии предпочитают помогать действующим конгрессменам, и тем самым уменьшают вероятность победы новичков.

В целом тенденция последних лет такова, что более $80 \%$ сенаторов и $90 \%$ членов Палаты представителей переизбираются на свои должности, что обеспечивают устойчивость социально-политического процесса в США.

Еще одна особенность внутренней политики состоит в том, что в стране уже долгое время существуют только две главные партии. В США, как в стране, имеющей двухпартийную политическую систему, все попытки создания третьей силы заканчиваются неудачей. В то же время, и в Конгрессе США и в законодательных органах штатов, есть независимые депутаты, формально не принадлежащие ни к одной из партий [7].

Особенно ярко бипартизм проявляется в период выборов. Оценки перспектив социально-политического процесса связаны с ре- 
зультатами предвыборной кампании в США 2016 г. По данным опросов, американцы выбирали из двух зол. Так, на вопрос, «почему вы готовы проголосовать за Клинтон», большинство ответили «потому что она не Трамп», в случае с Трампом, большинство готово голосовать за него, «потому что он не Клинтон». Около 4\% готовы были проголосовать за Госсекретаря только потому, что в случае победы она станет первой в истории США женщиной-президентом. Избиратели в основном разочарованы кампанией и недовольны тем, что кандидаты уделяли, куда большее внимание взаимным обвинениям, нежели внутриполитической повестке [11]. Характеристики голосования представлены на рис. 1.

\section{Кто голосует за Трампа}

Возраст
50-64
Пол
М
06разование
окончили колледж
Семейный доход
от \$75 тыс. в год
Семейное положение
женатые
Место жительства
жители маленьких городов

\section{Кто голосует за Клинтон}

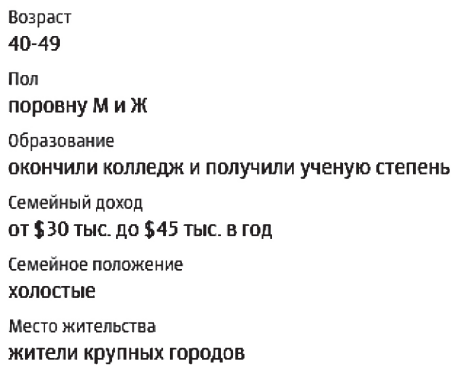

\section{Почему голосуют за Трампа}

Он не Клинтон

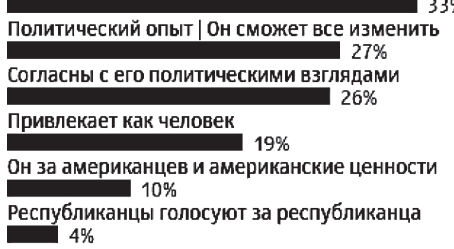

\section{Почему голосуют за Клинтон}

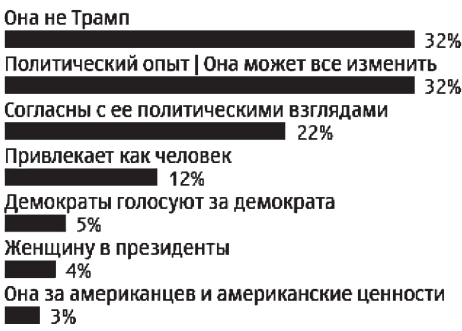

Рис. 1. Основания для голосования американцев [11]

Затраты на избирательную кампанию претендентов изображены на рис. 2. 

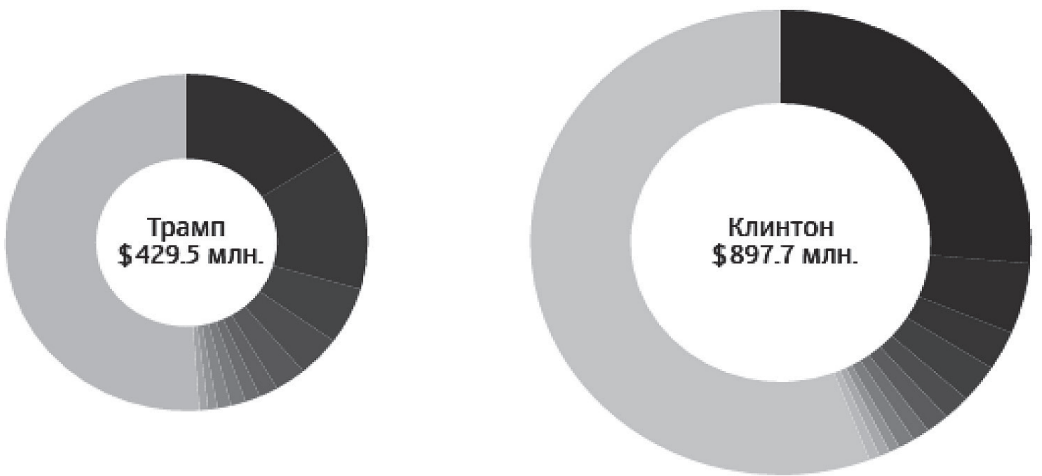

Рис. 2. Расходы кандидатов на предвыборную кампанию в сравнении [11]

Существуют следующие особенности социально-политического процесса в США. На рубеже XX-XXI вв. в США произошли события, которые в значительной степени повлияли на их процесс, и в политологии встал вопрос о собственно демократичности политического развития этого государства в современных условиях. Речь идет о терактах 11 сентября 2001 г, которые стали своеобразной вехой в новейшей истории США, да и, пожалуй, всего мира. Кардинальному пересмотру подверглась иерархия угроз американскому обществу. Изменилось представление о соотношении внутренней и внешней составляющих безопасности государства (первой стало придаваться большее, чем некогда, значение).

Ужесточение мер внутренней безопасности повлияло на взаимоотношения личности, общества и государства, повысив значение последнего и создав объективные предпосылки для ограничения прав и свобод граждан в интересах национальной безопасности. Причем характерной особенностью ситуации в США является поддержка самим обществом этих мер. Речь идет не только о проявлении терпимости и понимании тех ограничений и неудобств, которые сопровождают политику правительства, но и о широком инициативном движении граждан - росте числа добровольных пожарных команд, активизации соседских общин, потоке предложений по улучшению системы безопасности. В США созданы новые 
государственные институты (Министерство внутренней безопасности, Национальный совет по торговле), а также отмечается нарушение равновесия в системе сдержек и противовесов в сторону возвышения исполнительной власти.

В качестве важного и даже основополагающего компонента социально-политического процесса США выступает политическая культура. США - многонациональное государство, и американский процесс неизбежно приходится выстраивать с учетом мультикультурной и полиязычной социальной реальности.

По силе воздействия на социально-политический процесс в США ничто не сравнится с американским лоббизмом. Это явление политической жизни в США, в отличие от других государств, достигло небывалого масштаба и влияния. Причина тому - политическое устройство США, в котором изначально заложено наличие так называемых «точек доступа» - рычагов влияния на принятие политических решений. К концу XX - началу XXI в. отмечается резкое увеличение числа лоббистских организаций, изменение направленности лоббистской деятельности (помимо воздействия на законодательную и исполнительную власти лоббисты все больше апеллируют к общественному мнению) [9].

\section{Выводы}

1. США можно охарактеризовать как страну со стабильно-развивающимся социально-политическим процессом, неотъемлемой частью которого является двухпартийная система.

2. Социально-политический процесс отличается от политического по следующим параметрам:

- является более широким понятием;

- характеризует среду распространения политического процесса, показывая социальные риски американского общества;

- позволяет использовать теорию и практику международных отношений, ориентируясь на методы внешнеполитического курса США.

3. В динамике социально-политического процесса в США отмечается не только его стабильность, но и повышение роли электрон- 
ного лоббизма, усиление электронных рисков в связи со сложностью информации из-за глобализации и выхода информационных знаний за пределы национальных границ.

4. К особенностям социально-политического процесса в США можно также отнести сверхдержавность с ориентировкой на мягкую силу и агрессию (твердую силу), приоритет интересов национальной безопасности в противовес мировым задачам обеспечения прав и свобод граждан. Но проблема электронного лоббизма, глобализации, информационных рисков и безопасности требует содержательного рассмотрения в другой статье.

\section{Список литературы}

1. Алмонд Г. Гражданская культура, политические установки и демократии пяти наций // Антология мировой политической мысли в пяти томах / Том 2. Зарубежная политическая мысль ХХ в. М.: Мысль, 1997. С. 593.

2. Арон Р. Демократия и тоталитаризм // Антология мировой политической мысли в пяти томах / Том 2 Зарубежная политическая мысль ХХв. М.: Мысль, 1997. С. 508, 522-523.

3. Истон Д. Категории системного анализа политики // Антология мировой политической мысли в пяти томах / Том 2. Зарубежная политическая мысль ХХв. М.: Мысль, 1997. С. 630-631.

4. Мерриам Ч. Новые аспекты политики // Антология мировой политической мысли в пяти томах / Том 2. Зарубежная политическая мысль ХХ в. М.: Мысль, 1997. С. 176, 179.

5. Моргентау Г. Международная политика // Антология мировой политической мысли в пяти томах / Том 2. Зарубежная политическая мысль ХХ в. М.: Мысль, 1997. С. 502-503.

6. Парсонс Т. О понятии «политическая власть» // Антология мировой политической мысли в пяти томах / Том 2. Зарубежная политическая мысль ХХ в. М.: Мысль, 1997. С. 479, 483-484.

7. Полезная информация о США Valery Yalouskikh [Электронный ресурс] / сайт. URL: http://www.theusaconsult.com/ (дата обращения 18.03.2017). 
8. Политический процесс: сущность и содержание [Электронный ресурс]. Режим доступа: http://psyera.ru-/politicheskiy-process-ponyatiesushchnost-i-soderzhanie_8232.htm (дата обращения 15.04.16).

9. Субъекты и механизмы современного политического процесса в США [Электронный ресурс] / сайт. http://www.dissercat.com/content/ subekty-i-mekhanizmy-sovremennogo-politicheskogo-protsessa-v-ssha (дата обращения 11.02.2017).

10. Тищенко Г.Г. Что Дональд Трамп собирается сделать в сфере национальной безопасности, Российский институт стратегических исследований [Электронный ресурс] / Сайт. URL: www/riss.ru/ analitycs/39075/ (дата обращения 18.02.2017).

11. Сапронова Ю., Евтеев Е., Зейман А., РБК (РосБизнесКонсалтинг). Клинтон или Трамп: вся кампания в фактах и цифрах [Электронный ресурс] / сайт. URL: http://www.rbc.ru/politics/07/11/2016/5817 36d69a794798635041d1 (дата обращения 10.03.2017).

12. Almond Y., Verba S. Blackwell Encyclopedia of Political Thought. N.Y., 1987; Huntington S. American Politics: The Promise of Disharmony. N.Y., 1981; Nie N. Participation in America. N.Y., 1972.

13. Encyclipaedia Britannica [Электронный ресурс]. Режим доступа: http://www.encyclopedia.com/topic/-Arthur_F._Bentley.aspx (дата обращения 15.04.16)

\section{References}

1. Almond G. Grazhdanskaya kul'tura, politicheskie ustanovki i demokratii pyati natsiy [The Civic culture, political attitudes and democracy in five Nations]. Antologiya mirovoy politicheskoy mysli v pyati tomakh [Anthology of world political thought in five volumes] / vol. 2. Foreign political thought of the XX C. M.: Thought, 1997. P. 593.

2. Aron R. Demokratiya i totalitarizm [Democracy and totalitarianism]. Antologiya mirovoy politicheskoy mysli v pyati tomakh [Anthology of world political thought in five volumes] / vol. 2 Foreign political thought of the XX C. M.: Thought, 1997. P. 522, pp. 508-523.

3. Easton D. Kategorii sistemnogo analiza politiki [Category system analysis policy]. Antologiya mirovoy politicheskoy mysli v pyati to- 
makh [Anthology of world political thought in five volumes] / vol. 2. Foreign political thought of the XX C. M.: Thought., 1997. P. 630, p. 631.

4. Merriam H. Novye aspekty politiki [New aspects of politics]. Antologiya mirovoy politicheskoy mysli v pyati tomakh [Anthology of world political thought in five volumes] / vol. 2. Foreign political thought of the XX C. M.: Thought., 1997. P. 176, p. 179.

5. Morgentau G. Antologiya mirovoy politicheskoy mysli v pyati tomakh [Anthology of world political thought in five volumes] / vol. 2. Foreign political thought of the XX C. M.: Thought., 1997, pp. 502-503.

6. Parsons T. Antologiya mirovoy politicheskoy mysli v pyati tomakh [Anthology of world political thought in five volumes] / vol. 2. Foreign political thought of the XX C. M.: Thought., 1997. P. 479, pp. 483-484.

7. Poleznaya informatsiya o SShA Valery Yalouskikh [Helpful information about USA Valery Yalouskikh]. http://www.theusaconsult.com/ (accessed 18.03.2017).

8. Politicheskiy protsess: sushchnost'i soderzhanie [Political process: the nature and content]. http://psyera.ru-/politicheskiy-process-ponyatie-sushchnost-i-soderzhanie_8232.htm (accessed 15.04.16).

9. Subekty $i$ mekhanizmy sovremennogo politicheskogo protsessa $v$ SShA [Subjects and mechanisms of the modern political process in the United States]. http://www.dissercat.com/content/-subekty-i-mekhanizmy-sovremennogo-politicheskogo-protsessa-v-ssha (accessed 11.02.2017).

10. Tishchenko G.G. Chto Donal'd Tramp sobiraetsya sdelat'v sfere natsional'noy bezopasnosti, Rossiyskiy institut strategicheskikh issledovaniy [That Donald trump is going to do in the field of national security, the Russian Institute for strategic studies]. www/riss.EN/they/39075/ (accessed 18.02.2017).

11. Sapronov Yu., Evteev, E., Zaman A., RBC (RosBusinessConsulting). Klinton ili Tramp: vsya kampaniya $v$ faktakh $i$ tsifrakh [Clinton or trump: the entire campaign in facts and figures]. http://www.rbc.ru/politics-/07/11/2016/581736d69a794798635041d1 (accessed 10.03.2017). 
12. Almond Y., Verba S. Blackwell Encyclopedia of Political Thought. N.Y., 1987; Huntington S, American Politics: The Promise of Disharmony.

N.Y., 1981; Nie N. Participation in America. N.Y., 1972.

13. Encyclipaedia Britannica [Электронный ресурс] - Режим доступа: http://www.encyclopedia.com/topic/-Arthur_F._Bentley.aspx (accessed 15.04.16).

\section{ДАННЫЕ ОБ АВТОРАХ}

Бейдина Татьяна Евгеньевна, доктор политических наук, профессор, кафедра государственного, муниципального управления и политики Забайкальский государственный университет ул. Александро-Заводская, 30, г. Чита, Забайкальский край, 672039, Российская Федерачия beydina@inbox.ru

Бейдина Алена Романовна, аспирант, кафедра государственного, муниципального управления и политики Забайкальский государственный университет ул. Александро-Заводская, 30, г. Чита, Забайкальский край, 672039, Российская Федерачия alyonapersh@gmail.com

\section{DATA ABOUT THE AUTHORS}

Beydina Tatyana Evgenevna, Ph. D. in Political Science, Professor Trans-Baikal State 30, Aleksandro-Zavodskaya Str., Zabaikalsky Krai, 672039, Russian Federation beydina@inbox.ru

Beydina Alena Romanovna, Postgraduate Student Trans-Baikal State 30, Aleksandro-Zavodskaya Str., Zabaikalsky Krai, 672039, Russian Federation alyonapersh@gmail.com 